\title{
A Carlos Rodríguez Ajenjo: luchador incansable contra las adicciones
}

E

te número especial de Salud Pública de México está dedicado a honrar la memoria de Carlos Rodríguez Ajenjo, quien falleciera prematuramente el 9 de septiembre de 2010, cuando aún era Secretario Técnico del Consejo Nacional Contra las Adicciones (CONADIC).

Trabajar incansablemente para delinear y llevar a cabo acciones que eviten muertes prevenibles por enfermedad es un compromiso que asume todo servidor público del sector salud de México. Si alguien lo cumplió a cabalidad fue Carlos Rodríguez Ajenjo, en especial durante estos últimos cuatro años en que se desempeñó como Secretario Técnico del CONADIC y combatió las adicciones, principalmente la epidemia del tabaquismo que aqueja a nuestro país.

Está documentado que el tabaquismo en México se asocia con, por lo menos, 60 mil muertes al año; que ocasiona graves daños a la salud, al medio ambiente y a la economía tanto de fumadores como de no fumadores, y que es uno de los principales factores de riesgo para muerte prematura entre los mexicanos. Sin lugar a dudas es uno de los mayores problemas de salud pública en la nación.

Frente a la amenaza que representa el tabaquismo para la población mexicana, el sector salud, con el liderazgo de Carlos Rodríguez Ajenjo, a través del CONADIC, emprendió acciones que se han centrado en cuatro estrategias fundamentales: la prevención de la adicción al tabaco; la promoción de espacios $100 \%$ libres de humo de tabaco; el control y la regulación de los productos del tabaco; y la promoción para dejar de fumar y el tratamiento para lograrlo.

Igualmente, Carlos Rodríguez Ajenjo, al reconocer la importancia que tiene el contar con información actualizada de la epidemia, impulsó la realización de diversas encuestas que nos permiten tener información sobre la prevalencia de consumo de tabaco en diferentes segmentos de la población. Destacan la Encuesta Nacio- nal de Adicciones (ENA-2008), la Encuesta Global de Tabaco y Juventud (ETJ) y la Encuesta Global de Tabaco en Adultos (GATS-México).

Durante la presente administración se aprobó en el Congreso la Ley General para el Control del Tabaco (LGCT), la cual fue publicada por el Presidente de la República en mayo de 2008, así como el Reglamento de la LGCT, que fue publicado en mayo de 2009. Finalmente, el Acuerdo Secretarial para la Incorporación de Pictogramas y Leyendas de Advertencia en las cajetillas de cigarros fue publicado el 24 de diciembre de 2009 y entró en vigor el 25 de septiembre.

La contribución de Carlos Rodríguez Ajenjo fue crucial para llevar a buen término estas iniciativas. Lamentablemente para sus familiares, amigos y colegas, pero también para México entero, ya no le tocó ver las cajetillas ni los paquetes de productos del tabaco con los pictogramas y mensajes sanitarios que, a partir de la fecha mencionada, alertarán a la población sobre el riesgo que implica el consumo y la exposición al humo de estos productos.

La muerte del doctor Rodríguez Ajenjo deja un enorme vacío en el corazón de muchas personas que lo conocimos y trabajamos con él. No obstante, nos quedan sus enseñanzas, su ejemplo y el recuerdo de su amena conversación, así como la responsabilidad de seguir adelante con las acciones pendientes para combatir esta epidemia. Continuaremos trabajando para lograr el incremento en el precio del tabaco, pues está comprobado que es el mecanismo más eficaz para reducir su consumo, independientemente del nivel de ingreso de la población.

De lograr elevar el impuesto total sobre los cigarros en $75 \%$, cada cajetilla de cigarros llegaría a costar 48 o 49 pesos, lo que produciría una disminución de 2.79 millones de fumadores, casi 1 millón menos de muertes asociadas al tabaco y una recaudación de 43200 millones de pesos. 
El doctor Rodríguez Ajenjo contribuyó de manera importante en el desarrollo de políticas de control del tabaco más efectivas y mejor implementadas, y con base en los resultados de la Encuesta Nacional de Adicciones de 2008, constató el impacto positivo de estas medidas sobre el porcentaje de personas que fuman y la reducción paulatina de la proporción de fumadores en la población. *

Un pendiente urgente sobre el que Carlos ya estaba trabajando es la prevalencia del consumo de tabaco en jóvenes, ya que a diferencia de lo que se observa entre la población adulta, el consumo en adolescentes se ha incrementado en los últimos años. ${ }^{\neq}$

* La proporción de fumadores adultos con respecto a la población total disminuyó seis puntos porcentuales en la última encuesta. De acuerdo con la Encuesta Nacional de Adicciones de 2008, el consumo de tabaco ocurría en $20.4 \%$ de la población entre 12 y 65 años, y era mayor entre los hombres $(29.9 \%)$ que entre las mujeres (11.8\%).

* Los datos de la Encuesta de Tabaquismo en Jóvenes muestran que el porcentaje de adolescentes mexicanos de 12 a 15 años de edad que ha probado al menos un cigarro se incrementó de $51.1 \%$ en 2003 a $56.8 \%$ en 2006. De igual manera, la proporción de jóvenes que habían fumado en los últimos 30 días pasó de $19.9 \%$ a $24.9 \%$ en el mismo periodo, es decir, un incremento de 5 puntos porcentuales en sólo tres años.
Dentro de su legado, en lo que se refiere al control del tabaquismo en México, queda también la creación de la Oficina para el Control del Tabaco, que ha sido crucial para avanzar en las políticas públicas para controlar esta adicción, y la serie de publicaciones de Salud Pública de México, dedicadas a difundir información científica sobre el tabaquismo en México y que directamente han apoyado la toma de decisiones fundamentales para el control de este problema en nuestro país. Carlos nos deja un camino trazado y un gran trabajo en el área de adicciones que sin duda marcarán un parteaguas en la lucha contra este importante problema de salud pública en México.

Mauricio Hernández Ávila(1)

(1) Subsecretario de Prevención y Promoción de la Salud. Secretaría de Salud, México. 